\title{
Cardiopulmonary failure in children infected with Enterovirus A71
}

\author{
Shao-Hsuan Hsia, ${ }^{1,2}$ Jainn-Jim Lin ${ }^{1,2}$, Oi-Wa Chan ${ }^{1}$ and Tzou-Yien Lin ${ }^{3 *}$
}

\begin{abstract}
Enterovirus A71 (EV-A71) is one of the causative pathogens of hand, foot, and mouth disease (HFMD), which may cause severe neurological and cardiopulmonary complications in children. In this review, we discuss the pathogenesis, clinical manifestations, management strategy, and clinical outcomes of cardiopulmonary failure (CPF) in patients with EV-A71 infection.

The pathogenesis of CPF involves both catecholamine-related cardiotoxicity following brainstem encephalitis and vasodilatory shock due to cytokine storm. Sympathetic hyperactivity, including tachycardia and hypertension, are the early clinical manifestations of cardiopulmonary involvement, which may progress to pulmonary edema/ hemorrhage and/or CPF. The management strategy comprises multidisciplinary supportive treatment, including fluid management, positive pressure ventilation support, and use of milrinone, vasopressors, and inotropes. Some patients may require extracorporeal membrane oxygenation. Major neurological sequelae are almost inevitable once a child develops life-threatening illness. Long-term care of these children is an important medico-social issue.
\end{abstract}

Keywords: Enterovirus A71, Pulmonary edema, Brainstem encephalitis, Cardiopulmonary failure, Children

\section{Background}

Enterovirus A71 (EV-A71) was first described in 1969 [1]. Children infected with EV-A71 usually present with a self-limiting hand, foot, and mouth disease (HFMD); a majority of these patients show complete recovery. However, some children may develop severe systemic complications. Outbreaks of HFMD associated with high mortality rates have been reported across the world; however, a majority of these have occurred in the AsiaPacific region. The disorder is characterized by involvement of three major organ systems, i.e., central nervous system (CNS), respiratory system, and cardiovascular system. The severity of involvement of these systems shows a close correlation with clinical outcomes [2-8]. We reviewed articles pertaining to the pathogenesis, clinical manifestations, management, and outcomes of

\footnotetext{
* Correspondence: alinpid@gmail.com

${ }^{3}$ Department of Pediatrics, Chang Gung Memorial Hospital at Linkou, College of Medicine, Chang Gung University, No. 5, Fuxing Street, Guishan District, Taoyuan 333, Taiwan

Full list of author information is available at the end of the article
}

cardiopulmonary failure (CPF) in children with EV-A71 infection. We also highlight the general care principles, respiratory therapy, and cardiovascular support for $\mathrm{CPF}$ and provide practical considerations.

\section{Pathogenesis of cardiopulmonary failure}

The development of brainstem encephalitis (BE) represents a critical point in EV-A71-associated HFMD. Children with $\mathrm{BE}$ can subsequently develop autonomic nervous system (ANS) dysregulation, pulmonary edema (PE), heart failure, and CPF.

\section{Pulmonary edema}

Several mechanisms underlying the development of PE in patients with BE have been proposed. Significant brainstem insult induces enhanced secretion of catecholamines (especially norepinephrine) from the sympathetic nerve endings; this causes peripheral vasoconstriction, pulmonary venoconstriction, and reduced left ventricular compliance, which subsequently augments the 
intrathoracic blood volume with excessive hydrostatic pressure $[9,10]$. The second mechanism involves the release of some neurotransmitters (including neuropeptide Y) from the sympathetic nerves, which is linked to increased pulmonary capillary permeability [11]. The third mechanism involves extensive peripheral and CNS inflammatory responses, with abnormal production of cytokines [interleukin (IL)-10, IL-13, and interferongamma (IFN-g)] and depleted lymphocyte production, which increases endothelial permeability [12]. A complex interplay between all the three mechanisms may be involved in the pathogenesis of PE. There seems to be a decline in the incidence of $\mathrm{PE} / \mathrm{h}$ emorrhage after widespread adoption of stage-based management in Taiwan [8].

\section{Heart failure}

Myocardial injury and decreased contractility subsequently occur due to neurogenic stunned myocardium (NSM) [13] or norepinephrine cardiotoxicity [14]. Pathological findings of heart muscle in patients who died from EV-A71 infection were quite similar to those in cats with myocardial injury who were administered excessive norepinephrine.

In another study involving hemodynamic monitoring using pulmonary artery catheterization (PAC), two of the five patients initially showed elevation of pulmonary artery occlusion pressure (PAOP) to $>18 \mathrm{mmHg}$ (maximum PAOP: 22 and $25 \mathrm{mmHg}$ in the two patients); however, the PAOP eventually returned to $\leq 18 \mathrm{mmHg}$ (in 24 and $40 \mathrm{~h}$, respectively) in both patients. This suggested that intrathoracic hypervolemia and excessive hydrostatic pressure may not persist throughout the CPF stage. Notably, the systemic vascular resistance index (SVRI) of three of the five patients exceeded 1400 dynes $\cdot \mathrm{sec} / \mathrm{cm}^{5} / \mathrm{m}^{2}$ on at least one occasion; in addition, all four patients who underwent PAC monitoring for > $24 \mathrm{~h}$ showed decreases in SVRI to $\leq 1000$ dynes $\cdot \mathrm{sec} / \mathrm{cm}^{5}$ / $\mathrm{m}^{2}$ at some point. This indirectly suggests that the vasoconstrictive effect of the excessive catecholamine secretion resolves in the later part of the CPF stage, resulting in vasodilatory shock [15].

Therefore, the combined effect of NSM and vasodilatory shock may be the main cause of heart failure and mortality in patients with EV-A71 infection.

\section{Clinical manifestations}

As listed in the World Health Organization (WHO) Guide to Clinical Management for HFMD 2011 [16], most patients with severe disease exhibit serial changes in the involved organ systems. The disease course is characterized by progression through four clinical stages: 1) HFMD/herpangina; 2) CNS involvement; 3) ANS dysregulation; and 4) CPF. Although "cardiopulmonary failure" is considered as the final stage, the heart and lungs may be involved at a much earlier stage, possibly between CNS involvement and ANS dysregulation (Table 1). Therefore, concerted efforts to prevent CPF should be initiated from the time of appearance of the earliest signs of heart and lung involvement, such as prehypertension, tachycardia, tachypnea, and decreasing $\mathrm{PaO}_{2} /$ fraction of inspired oxygen $\left(\mathrm{FiO}_{2}\right)$. It is recommended that patients are managed in a pediatric intensive care unit.

\section{Management}

\section{General management}

Early identification of signs of deterioration is essential. Any patient with herpangina/HFMD who exhibits signs and symptoms of CNS involvement, such as frequent myoclonic jerks, limb weakness, seizure, ataxia, cranial nerve abnormality, or significant lethargy, should be subjected to close monitoring of cardiopulmonary function. In the early stages of cardiovascular deterioration, patients usually present with tachycardia and cold extremities, which may mimic the symptoms of hypovolemia. However, high-volume intravenous expansion during this period should be avoided as it may induce or aggravate pulmonary edema [16].

Intravenous immunoglobulin (IVIg) therapy is based on the assumption that the pooled immunoglobulins may neutralize the enterovirus, similar to that in neonatal enterovirus sepsis [21]. In addition, IVIg therapy may have an immunomodulatory effect in patients with proinflammatory cytokines [22, 23]. IVIg therapy is recommended for patients with CNS involvement [16]. However, if this therapy is not administered when patients progress to ANS dysregulation and CPF, it should be administered carefully as the large fluid volume may aggravate $\mathrm{CPF}$.

\section{Respiratory therapy}

Respiratory failure is caused by $\mathrm{PE} /$ hemorrhage and apnea during ANS dysregulation. It is a serious condition that may rapidly progress to the CPF stage. In patients with fulminant disease course, death may occur rapidly after sudden and severe hemoptysis [2].

Endotracheal intubation and positive pressure ventilation (PPV) may be considered in the following conditions: rapid deterioration of mental status [Glasgow coma scale $(\mathrm{GCS})<9$ ]; severe hypoxemia requiring a high $\mathrm{FiO}_{2}$; inability to maintain airway patency, such as frequent choking by saliva; apnea; and heart failure. A higher positive end-expiratory pressure of $6-8 \mathrm{cmH}_{2} \mathrm{O}$ is usually required to maintain oxygenation and prevent atelectasis [24].

High frequency oscillatory ventilation should be considered if very high $\mathrm{FiO}_{2}$ and mean airway pressure $(\mathrm{P} \overline{a w})$ are 
Table 1 Clinical manifestations of EV-A71 infections: four stages and management

\begin{tabular}{|c|c|c|c|c|}
\hline Stage & Signs of cardiopulmonary involvement & $\begin{array}{l}\text { Other clinical } \\
\text { manifestations }\end{array}$ & Laboratory/exam findings & $\begin{array}{l}\text { Management of } \\
\text { CPF }\end{array}$ \\
\hline $\begin{array}{l}\text { 1. HFMD/ } \\
\text { Herpangina }\end{array}$ & $>$ None & $\begin{array}{l}\triangleright \text { Vesicular rash on } \\
\text { hands, elbows, feet, knees } \\
\text { and buttocks } \\
>\text { Oral ulcers and } \\
\text { herpangina } \\
\triangleright \text { Fever } \\
\triangleright \text { Gl symptoms }\end{array}$ & $\triangleright$ Generally within normal limit & $>$ None \\
\hline $\begin{array}{l}\text { 2. CNS } \\
\text { Involvement }\end{array}$ & $\begin{array}{l}\triangleright \text { Prehypertension (systolic pressure between } 90 \\
\text { and } 95 \% \text { by age } \approx 105-115 \mathrm{mmHg} \text { for high risk } \\
\text { age groups) }[17] \\
>\text { Tachycardia (resting heart rate higher than } \\
\text { normal but }<150 / \mathrm{min} \text { ) and abnormal heart rate } \\
\text { variability( }[18][19] ;)\end{array}$ & $\begin{array}{l}>\text { Myoclonic jerk } \\
\triangleright \text { Meningism } \\
>\text { Ataxia, tremors } \\
\triangleright \text { Lethargy } \\
>\text { Limb weakness and } \\
\text { Polio-like syndrome } \\
>\text { Altered mental status } \\
>\text { Generalized tonic- } \\
\text { clonic convulsion }\end{array}$ & $\begin{array}{l}>\text { CSF pleocytosis } \\
>\text { MRl: high signal intensities on T2 } \\
\text { weighted images in brainstem and } \\
\text { spinal cord [20] }\end{array}$ & $\begin{array}{l}>\text { Limited fluid } \\
\text { replacement } \\
\text { therapy } \\
\triangleright \text { Early } \\
\text { intubation and } \\
\text { PPV } \\
\triangleright \text { IVlg }\end{array}$ \\
\hline $\begin{array}{l}\text { 3. ANS } \\
\text { Dysregulation }\end{array}$ & $\begin{array}{l}>\text { Inappropriate tachycardia (resting heart rate }> \\
150 / \text { min) } \\
\triangleright \text { Severe hypertension (systolic pressure }>95 \% \\
\text { by age } \approx 115-120 \text { mmHg for high risk age } \\
\text { groups) }[17] \\
\triangleright \text { Tachypnea } \\
\triangleright \text { Hemoptysis, pink frothy sputum } \\
\triangleright \text { Low Pao2: Fio2 ratio } \\
\triangleright \text { Chest radiography: PE/H }\end{array}$ & $\begin{array}{l}>\text { Hyperglycemia (> } 150 \\
\mathrm{mg} / \mathrm{dL} \text { ) } \\
>\text { Profuse sweating } \\
>\text { Cranial nerve } \\
\text { abnormality and GCS } \\
\text { deterioration }\end{array}$ & $\begin{array}{l}>\text { Hypoxemia } \\
>\text { Hyperglycemia }\end{array}$ & $\begin{array}{l}\triangleright \text { Intubation } \\
\text { and PPV } \\
\triangleright \text { HFOV } \\
\triangleright \text { Milrinone }\end{array}$ \\
\hline 4. CPF & $\begin{array}{l}>\text { Hypotension } \\
>\text { Low cardiac output } \\
>\text { Signs of poor perfusion } \\
>\text { Absence of spontaneous respiration though } \\
\text { pulmonary edema improves }\end{array}$ & $\begin{array}{l}>\text { Coma, paralysis } \\
\triangleright \text { Neurological sequelae }\end{array}$ & $\begin{array}{l}>\text { Elevated troponin I and cardiac } \\
\text { enzyme } \\
\triangleright \text { Lactic acidosis } \\
\triangleright \text { Poor left ventricle ejection } \\
\text { fraction }\end{array}$ & $\begin{array}{l}\triangleright \text { Dopamine } \\
\text { and } \\
\text { epinephrine } \\
\triangleright \text { ECMO } \\
\triangleright \text { Volume } \\
\text { expansion }\end{array}$ \\
\hline
\end{tabular}

required to maintain oxygenation, as suggested in acute respiratory distress syndrome [25].

\section{Cardiovascular support}

Milrinone is a phosphodiesterase 3 inhibitor that promotes cardiac contractility and decreases both pulmonary and systemic vascular resistance [26]. Milrinone has also been shown to exhibit an anti-inflammatory effect [27]. In a historical controlled case series, the milrinonetreated group had lower mortality, decreased sympathetic tachycardia, and marked decrease in IL-13 level [28]. In a randomized controlled trial, the milrinone treatment group showed lower 1-week mortality and longer median duration of ventilator-free period than the control group [29]. Early initiation of milrinone therapy is recommended in patients who show echocardiographic evidence of impaired heart function, even if the blood pressure and organ perfusion are at an acceptable level $[24,30]$.

Excessive catecholamines may induce PE, cause myocardial damage, and augment virus infection; therefore, WHO guidelines do not recommend the use of dopamine, epinephrine, or norepinephrine [13, 16, 31, 32]. However, the adverse effects of catecholamines are mainly attributable to their $\alpha 1$-adrenergic effect [33] (which occurs after the use of norepinephrine and at high dopamine, epinephrine, and dobutamine infusion rates), and application of extracorporeal membrane oxygenation (ECMO) in infants and toddlers can cause severe complications [34]. Therefore, prior to considering ECMO, low-intermediate doses of dopamine $(\leq 10 \mathrm{mcg} /$ $\mathrm{kg} / \mathrm{min})$ and epinephrine $(\leq 0.1 \mathrm{mcg} / \mathrm{kg} / \mathrm{min})$ may be administered in high-risk patients if the blood pressure decreased to below the normal range (approximately 85-90 mmHg systolic pressure) [35].

ECMO is the last rescue treatment for refractory CPF. In a retrospective study of 13 children (mean age, $16 \pm$ 10 months) with EV-A71 CPF, the clinical manifestations and outcomes (2000-2008, present cohort) were compared with those of 10 other children (1998-2000, past cohort). The present cohort showed significantly better neurological outcomes (46\% vs. $0 \%, P=0.005)$ and a significantly higher survival rate $(77 \%$ vs. $30 \%, P=0.024)$ compared with the past cohort [36]. Unfortunately, some of the survivors had mild-to-severe neurological sequelae. ECMO can be considered for patients with refractory hypotension, those with signs of poor end-organ perfusion (such as profound lactic acidosis and oliguria) 
or poor left ventricle contractility (on echocardiography or hemodynamic monitoring), and those who require high doses of inotropes [16, 24].

Other suggested treatments include $\alpha$ and $\beta$ blockers, vasodilators, and diuretics [24]. In a rat model of PE, prazosin ( $\alpha 1$ receptor blocker) was shown to preserve cardiac output, reverse neutrophil infiltration in the lungs, and prevent pulmonary hemorrhagic edema; however, those treated with propranolol (a $\beta$-receptor blocker) died within $2 \mathrm{~h} 30 \mathrm{~min}$. A case report also documented successful treatment of PE with phentolamine in a human [37]. No trials of vasodilators and diuretics in this setting have been conducted; therefore, current guidelines do not recommend their routine use. The present understanding of the pathogenetic mechanisms and the current management options for EV-A71associated CPF are illustrated in Fig. 1. First, the virus induces a systemic inflammatory response and causes $B E$. Second, BE induces excessive secretion of catecholamines, followed by decreased left ventricular myocardial contractility, diastolic dysfunction, and peripheral vasoconstriction. Third, these three effects combined with neurotransmitter-induced changes in pulmonary capillary permeability and fluid overload cause PE/ hemorrhage. Furthermore, catecholamine therapy (especially norepinephrine) may enhance the viral activity and the inflammatory response. Accordingly, vaccines (rapid progress has been made in the development of EV-A71 vaccines [38]) can be used to prevent virus infection, IVIg can be used to reduce systemic inflammatory response, fluid overload can be avoided, milrinone can be administered at an early stage to prevent pulmonary vascular congestion, PPV can be used to prevent abnormal alveolar gas exchange resulting from $\mathrm{PE} /$ hemorrhage, vasopressors can be used when necessary, and timely use of ECMO can be considered as a life-saving measure.

\section{Outcome}

In a long-term follow up study, of 28 patients who survived $\mathrm{CPF}, 18$ (64\%) had limb weakness and atrophy, 17 (61\%) required tube feeding, and $16(57 \%)$ required ventilator support. In addition, 21 of 28 patients (75\%) exhibited delayed neurodevelopment as assessed using the Denver Developmental Screening Test (DDST II) [39]. These survivors require long-term medical care, socioeconomic assistance, and educational support.

\section{Conclusions}

During the last 20 years, we have progressed from ignorance to a better understanding of EV-A71-caused HFMD. CPF is characterized by PE, NSM, and vasodilatory shock. There is no commercially available antiviral drug against EV71 to prevent viral replication or prevent CPF. IVIg therapy, milrinone administration, and stage-

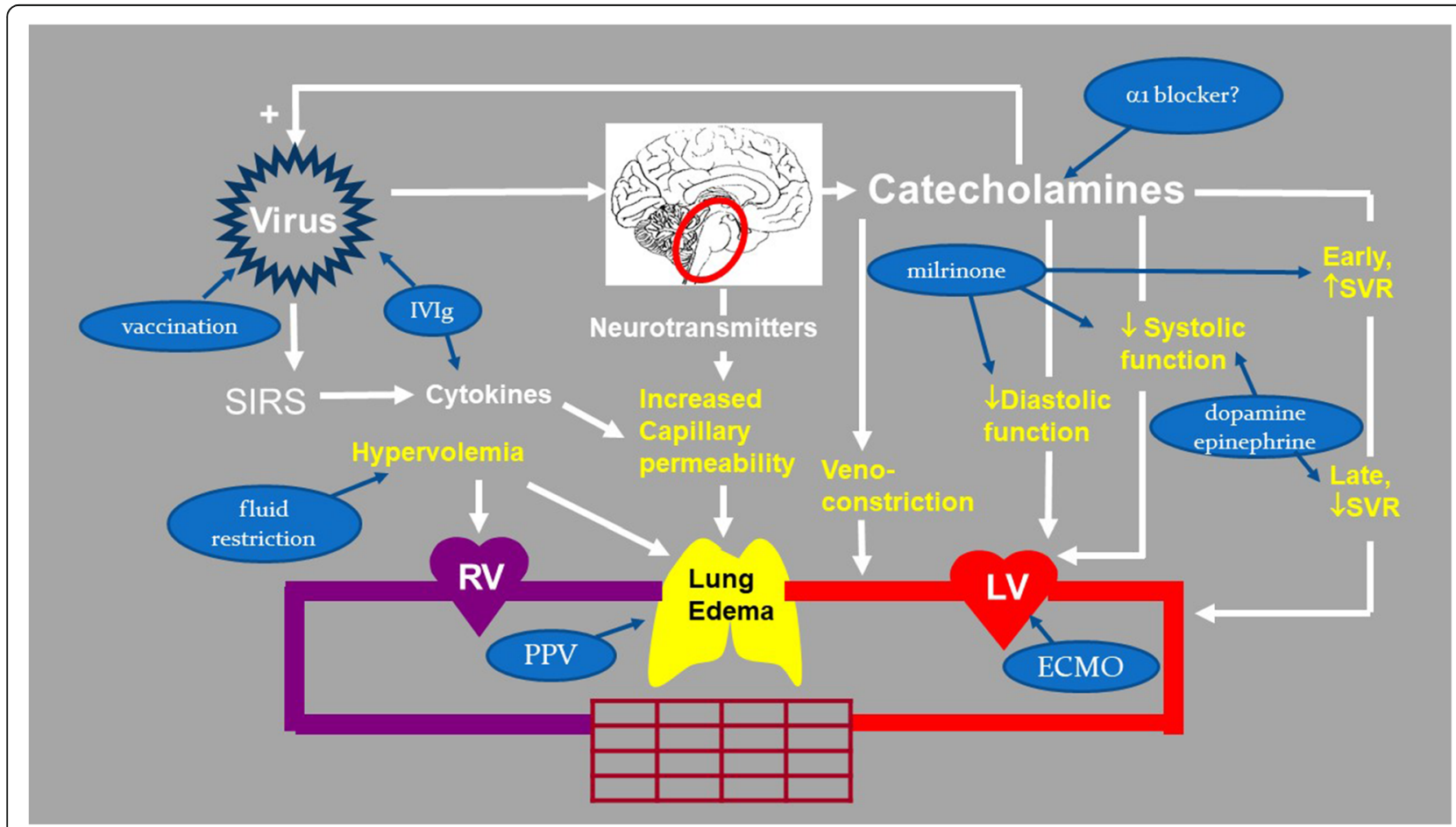

Fig. 1 Schematic illustration of the pathogenesis and the available management options for EV-A71-associated cardiopulmonary failure. Text in white font indicates the direct causes of cardiopulmonary failure. Text in yellow font indicates the mechanisms. Text within blue circles indicates the specific management options for CPF. RV: right ventricle; LV: left ventricle 
based management appear to be associated with better outcomes. Identifying the signs of disease progression, anticipating the development of $\mathrm{CPF}$, and providing appropriate multidisciplinary supportive treatment are key tenets of management. ECMO seems to be the last rescue approach for critically ill children with refractory CPF.

\section{Abbreviations}

ANS: Autonomic nervous system; BE: Brainstem encephalitis; CNS: Central nervous system; CPF: Cardiopulmonary failure; ECMO: Extracorporeal membrane oxygenation; EV-A71: Enterovirus $\mathrm{A} 71$; $\mathrm{FiO}_{2}$ : Fraction of inspired oxygen; GCS: Glasgow coma scale; HFMD: Hand, foot, and mouth disease; IVlg: Intravenous immunoglobulin; NSM: Neurogenic stunned myocardium; PE/H: Pulmonary edema/hemorrhage; PAC: Pulmonary artery catheterization; PAOP: Pulmonary artery occlusion pressure; P $\overline{a W}$ : Mean airway pressure; PPV: Positive pressure ventilation; SVRI: Systemic vascular resistance index; WHO: World Health Organization

\section{Acknowledgements}

We would like to thank the authors whose work has been reviewed and cited in this paper. We thank www.eago.com for providing English editing.

\section{Authors' contributions}

$\mathrm{SHH}$ collected the literature and designed and wrote the manuscript. OWC collected the literature. JJL edited and prepared the manuscript for submission. TYL decided the structure of this article, provided important references, and made suggestions during the writing. All authors read and approved the final manuscript.

\section{Funding}

This work was not financially supported by any grant.

\section{Availability of data and materials}

Not applicable.

\section{Ethics approval and consent to participate}

Not applicable.

\section{Consent for publication}

Not applicable.

\section{Competing interests}

The authors declare that they have no competing interests.

\section{Author details}

'Division of Pediatric Critical Care Medicine, Department of Pediatrics, Chang Gung Memorial Hospital at Linkou, College of Medicine, Chang Gung University, Taoyuan, Taiwan. ${ }^{2}$ Department of Pediatric Respiratory Therapy, Chang Gung Memorial Hospital at Linkou, College of Medicine, Chang Gung University, Taoyuan, Taiwan. ${ }^{3}$ Department of Pediatrics, Chang Gung Memorial Hospital at Linkou, College of Medicine, Chang Gung University, No. 5, Fuxing Street, Guishan District, Taoyuan 333, Taiwan.

Received: 15 July 2019 Accepted: 31 March 2020

Published online: 16 April 2020

\section{References}

1. Schmidt NJ, Lennette $\mathrm{EH}, \mathrm{Ho} H \mathrm{H}$. An apparently new enterovirus isolated from patients with diseases of the central nervous system. J Infect Dis. 1974; 129:304-9.

2. Chang LY, Huang YC, Lin TY. Fulminant neurologic pulmonary oedema with hand, foot, and mouth disease. Lancet. 1998:352(9125):367-8.

3. Deibel R, Gross LL, Collin DN. Isolation of a new enterovirus. Proc Soc Exp Biol Med. 1975;148:203-7

4. Tagaya I, Tachibana K. Epidemic of hand, foot, mouth disease in Japan, 1972-1973: difference in epidemiologic and virologic features from the previous one. Jpn J Med Sci Biol. 1975:28:231-4.

5. Gilbert GL, Dickson KE, Waters MJ, Kennet ML, Land SA, Sneddon M Outbreak of entervirus 71 infection in Victoria, Australia, with a high incidence of neurological involvement. Pediatr Infect Dis J. 1988;7:484-8.
6. Sindarov LM, Chumakov MP, Voroshilova MK, Bojinov S, Vasilenko SM, Iordanov I, et al. Epidemiological, clinical, and pathomorphological characteristics of epidemic poliomyelitis-like disease caused by enterovirus 71. J Hyg Epidemiol Microbiol Immunol. 1979:23:284-95.

7. Nagy G, Takatsy S, Kukan E, Mihaly I, Domok I. Virological diagnosis of enterovirus 71 infections: experience gained during an epidemic of acute CNS disease in Hungary in 1978. Arch Virol. 1982;71:217-27.

8. Hsia SH, Wu CT, Chang JJ, Lin TY, Chung HT, Lin KL, et al. Predictors of unfavorable outcomes in enterovirus 71-related cardiopulmonary failure in children. Pediatr Infect Dis J. 2005;24(4):331-4.

9. Baumann A, Audibert G, McDonnell J, Mertes PM. Neurogenic pulmonary edema. Acta Anaesthesiol Scand. 2007;51(4):447-55.

10. Inamasu J, Sugimoto K, Yamada Y, Ganaha T, Ito K, Watabe T, et al. The role of catecholamines in the pathogenesis of neurogenic pulmonary edema associated with subarachnoid hemorrhage. Acta Neurochir. 2012:154(12): 2179-84.

11. Agrawal A, Timothy J, Pandit L, Kumar A, Singh GK, Lakshmi R. Neurogenic pulmonary oedema. Eur J Gen Med. 2007;4(1):25-32.

12. Wang SM, Lei HY, Huang KJ, Wu JM, Wang JN, Yu CK, et al. Pathogenesis of enterovirus 71 brainstem encephalitis in pediatric patients: roles of cytokines and cellular immune activation in patients with pulmonary edema. J Infect Dis. 2003;188:564-70.

13. Biso S, Wongrakpanich S, Agrawal A, Yadlapati S, Kishlyansky M, Figueredo V. A review of neurogenic stunned myocardium. Cardiovasc Psychiatry Neurol. 2017;2017:5842182.

14. Fu Y, Chi C, Lin N, Cheng C, Jan S, Hwang B, et al. Comparison of heart failure in children with enterovirus 71 rhombencephalitis and cats with norepinephrine cardiotoxicity. Pediatr Cardiol. 2006;27:577-84

15. Wu JM, Wang JN, Tsai YC, Liu CC, Huang CC, Chen YJ, et al. Cardiopulmonary manifestations of fulminant enterovirus 71 infection. Pediatrics. 2002;109(2):E26.

16. WHO Regional Office for the Western Pacific. A Guide to clinical management and public health response for hand, foot and mouth disease (HFMD). 2011. https://apps.who.int/iris/handle/10665/207490.

17. National High Blood Pressure Education Program Working Group on High Blood Pressure in Children and Adolescents. The Fourth Report on the Diagnosis, Evaluation, and Treatment of High Blood Pressure in Children and Adolescents. Pediatrics. 2004;114(2 Suppl):555-76.

18. Chang LY, Lin TY, Hsu KH, Huang YC, Lin KL, Hsueh C, et al. Clinical features and risk factors of pulmonary oedema after enterovirus-71-related hand, foot, and mouth disease. Lancet. 1999:354:1682-6.

19. Lin MT, Wang JK, Lu FL, Wu ET, Yeh SJ, Lee WL, et al. Heart rate variability monitoring in the detection of central nervous system complications in children with enterovirus infection. J Crit Care. 2006:21:280-6.

20. Ooi M, Wong S, Lewthwaite P, Cardosa MJ, Solomon T. Clinical features, diagnosis, and management of enterovirus 71. Lancet Neurol. 2010;9(11): 1097-105.

21. McKinney RE Jr, Katz SL, Wilfert CM. Chronic enteroviral meningoencephalitis in agammaglobulinemic patients. Rev Infect Dis. 1987;9(2):334-56.

22. Lin Z, Hsia S, Huang Y, Wu C, Chang L. Proinflammatory cytokine reactions in enterovirus 71 infections of the central nervous system. Clin Infect Dis. 2003:36:269-74

23. Wang SM, Lei HY, Huang MC, et al. Modulation of cytokine production by intravenous immunoglobulin in patients with enterovirus 71-associated brainstem encephalitis. J Clin Virol. 2006a;37(1):47-52.

24. 2014 Recommendations for the Clinical Management of Patients with Enterovirus A71 Infection with Severe Complications. Taiwan's Enterovirus Ad Hoc Committee and the Center for Disease Control in Taiwan. 2014. https://www.cdc.gov.tw/downloadfile.aspx?fid=FE6526F45F6DD913.

25. Sud S, Sud M, Friedrich JO, Meade MO, Ferguson ND, Wunsch H, et al. High frequency oscillation in patients with acute lung injury and acute respiratory distress syndrome (ARDS): systematic review and meta-analysis. BMJ. 2010; 340:c2327.

26. Packer M, Carver JR, Rodeheffer RJ. PROMISE study research group. Effect of oral milrinone on mortality in severe chronic heart failure. The PROMISE study research group. N Engl J Med. 1999;325:1468-75

27. Gong $M$, Lin $X Z$, Lu GT. Preoperative inhalation of milrinone attenuates inflammation in patients undergoing cardiac surgery with cardiopulmonary bypass. Med Princ Pract. 2012;21:30-5.

28. Wang SM, Lei HY, Huang MC, Wu JM, Chen CT, Wang JN, et al. Therapeutic efficacy of milrinone in the management of enterovirus 71-induced pulmonary edema. Pediatr Pulmonol. 2005;39:219-23. 
29. Chi CY, Khanh TH, Tseng FC, Wang SM, Lin CC, Wu HC, et al. Milrinone therapy for enterovirus 71-induced pulmonary edema and/or neurogenic shock in children: a randomized controlled trial. Crit Care Med. 2013;41(7): 1754-60.

30. Wang JN, Yao CT, Yeh CN, Huang CC, Wang SM, Liu CC, et al. Critical management in patients with severe enterovirus 71 infection. Pediatr Int. 2006b;48(3):250-6.

31. Liao YT, Wang SM, Wang JR, Yu CK, Liu CC. Norepinephrine and epinephrine enhanced the infectivity of enterovirus 71. PLoS One. 2015; 10(8):e0135154.

32. Lu WH, Hsieh KS, Lu PJ, Wu YS, Ho WY, Cheng PW, et al. Different impacts of alpha- and beta-blockers in neurogenic hypertension produced by brainstem lesions in rat. Anesthesiology. 2014;120(5):1192-204.

33. Noori S, Seri I. Neonatal blood pressure support: the use of inotropes, lusitropes, and other vasopressor agents. Clin Perinatol. 2012;39(1):221-38.

34. Deshpande SR, Maher KO, Morales DL. Mechanical circulatory support in children: challenges and opportunities. Progress Pediatr Cardiol. 2016;43:31-41

35. Hazinski MF. Nursing Care of the Critically ill Child. 2nd ed. St. Louis: Mosby Year Book; 1992

36. Jan S, Lin S, Fu Y, Chi CS, Wang CC, Wei HJ, et al. Extracorporeal life support for treatment of children with enterovirus 71 infection-related cardiopulmonary failure. Intensive Care Med. 2010;36:520-7.

37. Davison D, Chawla L, Selassie L, Tevar R, Junker C, Seneff M. Neurogenic pulmonary edema successful treatment with IV phentolamine. Chest. 2012; 141(3):793-5.

38. Li R, Liu L, Mo Z, Wang X, Xia J, Liang Z, et al. An inactivated enterovirus 71 vaccine in healthy children. N Engl J Med. 2014;370(9):829-37.

39. Chang LY, Huang LM, Gau SSF, Wu YY, Hsia SH, Fan TY, et al. Neurodevelopment and cognition in children after enterovirus 71 infection. N Engl J Med. 2007;356:1226-34.

\section{Publisher's Note}

Springer Nature remains neutral with regard to jurisdictional claims in published maps and institutional affiliations.

Ready to submit your research? Choose BMC and benefit from:

- fast, convenient online submission

- thorough peer review by experienced researchers in your field

- rapid publication on acceptance

- support for research data, including large and complex data types

- gold Open Access which fosters wider collaboration and increased citations

- maximum visibility for your research: over $100 \mathrm{M}$ website views per year

At $\mathrm{BMC}$, research is always in progress.

Learn more biomedcentral.com/submissions 